\title{
Detecting Elusive Intermediates in Carbohydrate Conversion: A Dynamic Ensemble of Acyclic Glucose-Catalyst Complexes
}

\author{
Meier, Sebastian; Karlsson, Magnus; Jensen, Pernille Rose
}

Published in:

ACS Sustainable Chemistry \& Engineering

Link to article, DOI:

10.1021/acssuschemeng.7b00985

Publication date:

2017

Document Version

Peer reviewed version

Link back to DTU Orbit

Citation (APA):

Meier, S., Karlsson, M., \& Jensen, P. R. (2017). Detecting Elusive Intermediates in Carbohydrate Conversion: A Dynamic Ensemble of Acyclic Glucose-Catalyst Complexes. ACS Sustainable Chemistry \& Engineering, 5(6), 5571-5577. https://doi.org/10.1021/acssuschemeng.7b00985

\section{General rights}

Copyright and moral rights for the publications made accessible in the public portal are retained by the authors and/or other copyright owners and it is a condition of accessing publications that users recognise and abide by the legal requirements associated with these rights.

- Users may download and print one copy of any publication from the public portal for the purpose of private study or research.

- You may not further distribute the material or use it for any profit-making activity or commercial gain

- You may freely distribute the URL identifying the publication in the public portal 


\title{
Detecting Elusive Intermediates in Carbohydrate Conversion: A Dynamic Ensemble of Acyclic Glucose-Catalyst Complexes
}

\author{
Sebastian Meier, ${ }^{1 *}$ Magnus Karlsson, ${ }^{2}$ and Pernille Rose Jensen ${ }^{2} *$
}

${ }^{1}$ Department of Chemistry, Technical University of Denmark, Kemitorvet Builing 207, 2800 Kgs. Lyngby, Denmark

${ }^{2}$ Department of Electrical Engineering, Technical University of Denmark, Ørsteds Plads Building Building 349, 2800 Kgs. Lyngby, Denmark

*Corresponding authors:

S.Meier: semei@kemi.dtu.dk.

P.R.Jensen:peroje@elektro.dtu.dk.

KEYWORDS

acyclic tautomer; epimerization; glucose; homogenous catalysis; pre-steady-state; reaction intermediate 


\begin{abstract}
The role of acyclic carbohydrates in pathways towards value-added chemicals has remained poorly characterized due to the low population of acyclic forms, and due to their instability under reaction conditions. We conduct steady-state and pre-steady state measurements by direct reaction progress monitoring with sensitivity-optimized NMR spectroscopy in the molybdatecatalyzed epimerization of glucose to mannose. We detect an exchanging pool of at least five acyclic glucose-catalyst complexes under near-optimum reaction conditions. In the presence of catalyst, the acyclic glucose population increases within few seconds prior to reaching a steady state. Exchange between the acyclic intermediates increases at conditions that favor epimerization. Species accounting for less than $0.05 \%$ of total glucose can be monitored with sub-second time resolution to allow kinetic analysis of intermediate formation and catalytic conversion. Epimerization occurs 2-3 orders of magnitude-fold faster than the binding of acyclic glucose to the catalyst at near-optimum reaction conditions. The current study brings insight into the nature of acyclic intermediate-catalyst complexes of very low population and into experimental strategies for characterizing very minor intermediates in carbohydrate conversion to value-added compounds.
\end{abstract}




\section{INTRODUCTION}

The need for establishing sustainable future economies to cover societal demands of energy and materials is widely recognized. Hence, considerable attention is being paid to the bio- and chemocatalytic conversion of biomass to value-added products. Carbohydrates represent most of the biomass-derived compounds. A step towards value-added, bio-derived products can be taken by converting carbohydrates to platform chemicals and upgrading them to less abundant functional molecules. ${ }^{1,2}$ Glucose is the most abundant carbohydrate in nature as the product of photosynthesis. C6 carbohydrates such as glucose exist in solution as equilibria of tautomeric forms, including cyclic pyranose and (five-membered) furanose forms alongside acyclic aldehyde and hydrate forms. Owing to its all-equatorial substituents, glucose is more stable than other C6 aldopyranoses in the predominant, six-membered pyranose form. ${ }^{3}$

Nuclear magnetic resonance (NMR) spectroscopy is a widely employed method for the study of carbohydrate tautomeric equilibria in solution. ${ }^{3,4}$ These studies face analytical challenges due to the small ${ }^{1} \mathrm{H}$ NMR chemical shift dispersion and the presence of various tautomeric forms, leading to rather complex spectra even for solutions of a single carbohydrate. Challenges in the structural characterization of carbohydrates are paralleled by challenges in studying interactions with catalysts of the various, dynamically equilibrating tautomeric forms. The catalytic conversion of glucose to bio-derived products is often assumed to use furanose or acyclic forms as substrates, which are minor components in the presence of $\sim 98 \%$ pyranose form even at 373 K. As an example, it has remained unclear, whether furanose or acyclic forms are the substrates in the extensively studied reactions to the platform chemical hydroxymethylfurfural..$^{5-7}$ The 
stability of glucopyranose forms thus poses a potential challenge in using glucose as a substrate for the production of green chemicals and in analyzing the reactivity of rare glucose forms.

Experimental studies of acyclic glucose forms are particularly demanding due to their low abundance in aqueous and non-aqueous solvents, accounting for approximately $0.01 \%$ at $303 \mathrm{~K}$ and $0.04 \%$ at $373 \mathrm{~K} .{ }^{3,8}$ Hence, the acyclic forms are the least studied tautomeric forms of glucose and of other C6 carbohydrates, ${ }^{4}$ not least with regards to their reactivity. At the same time, acyclic forms occur as high-energy intermediates in the interconversion of cyclic forms and can be considered as activated substrates for reaction pathways that can use acyclic carbohydrates. As an example, the production of rare sugars for chemical, medical or nutritional applications hinges on isomerizations and epimerizations of more abundant sugars mostly via acyclic pathways. ${ }^{9}$

Rare sugars can function as low-calorie sweeteners, bulking agents and building blocks of drugs and natural products, but convenient, efficient and cost-effective preparation methods have remained limiting. ${ }^{10}$ Most epimerases are only active on carbohydrates that are modified, for instance with phosphate or nucleotide groups. Such requirements on the substrate drastically restrict the use of epimerases in industrial applications, alongside other limitations such as the usually narrow $\mathrm{pH}$ and temperature range that is suitable for enzymes. ${ }^{9}$ Chemocatalysis can provide alternative chemical pathways to those offered by biological systems and has recently gained additional interest due to the development of heterogeneous catalysts for glucose epimerization, including tin-containing silicates or molybdenum-based catalysts. ${ }^{9}, 11-13$ The epimerization of aldoses by concurrent $\mathrm{C} 2-\mathrm{C} 3$ bond cleavage and $\mathrm{C} 1-\mathrm{C} 3$ bond formation is known as the Bílik reaction. ${ }^{14,15}$ In its original form, the reaction is catalyzed by molybdate and favored by temperatures near $363 \mathrm{~K}$ and by slightly acidic $\mathrm{pH}$. Epimerization through $\mathrm{C} 2-\mathrm{C} 3$ 
bond cleavage and $\mathrm{C} 1-\mathrm{C} 3$ bond formation can be identified by using site-specifically ${ }^{13} \mathrm{C}$ or ${ }^{2} \mathrm{H}$ isotope labeled substrate to track the label exchange between the $\mathrm{C} 1$ position in the substrate and the C2-position in its epimer. This mechanism involving intramolecular carbon exchange has been identified both for the homogeneous reaction and for heterogeneous variants..$^{9}$ 11-13 Computational studies have suggested a preferential adsorption of acylic glucose onto some catalysts, but experimental observations of reaction intermediates have remained sparse. ${ }^{16,17}$

Here, we explore the usefulness of a sensitivity-enhanced version of ${ }^{13} \mathrm{C}$ NMR spectroscopy to overcome challenges of conventional ${ }^{1} \mathrm{H}$ NMR in the detection of activated, catalyst-bound states of rare tautomeric forms, especially of the acyclic form of glucose. In the majority of cases, NMR analysis deals with stable reaction products, studies equilibria or follows reactions in real time on the minutes to hour timescales. ${ }^{18-20}$ Emerging sensitivity-improving hyperpolarization (HP) technique can enhance NMR signals by several orders of magnitude ${ }^{21}$ and enable real-time observations of transient reaction intermediates and pre-steady state measurements for catalyzed reactions. ${ }^{22-24}$ We show that HP-NMR (hyperpolarized NMR) can directly observe the formation of an ensemble of acyclic glucose intermediates in complex with the catalyst without trapping the intermediates (Figure 1) by chemical means or by low temperature. Rather, reactions are tracked at conditions that are optimal for product formation with sub-second time resolution. The HP-NMR experiments are combined with complementary high-resolution steady-state NMR experiments under conditions that decelerate the reaction. These complementary experiments on stabilized samples corroborate the detection of a dynamically exchanging ensemble between acyclic glucose and metal catalyst during reaction progress under optimum conditions. 

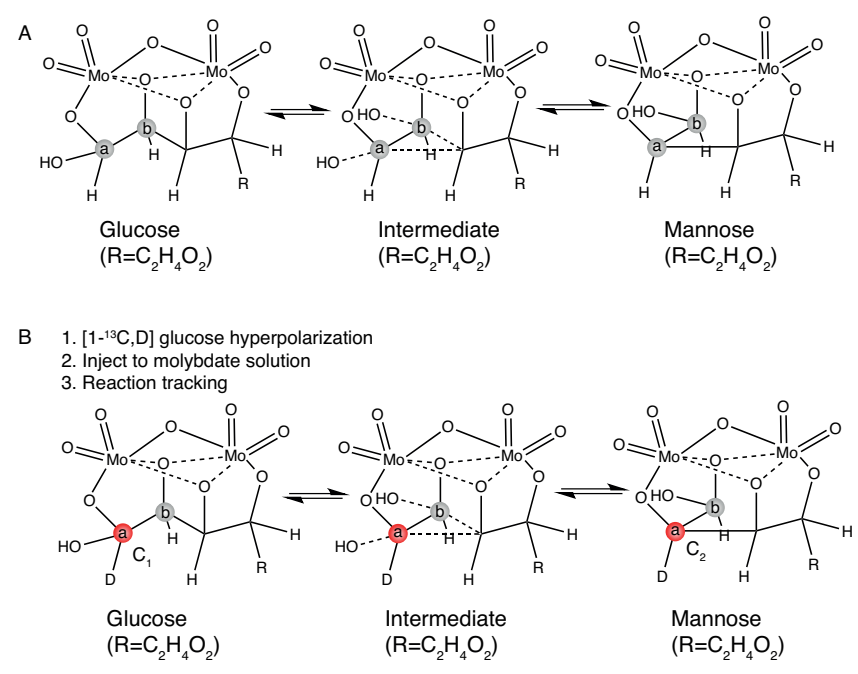

Figure 1. A) Reaction scheme for the molybdate-catalyzed glucose epimerization. $.^{14,} 15,25$ Molybdate is coordinated to the open chain hydrated aldehyde form of glucose. A 1,2 carbon shift can occur by concurrent C2-C3 bond cleavage and C1-C3 bond formation. B) Experimental design for reaction tracking using hyperpolarized glucose. $\left[1-{ }^{13} \mathrm{C}, \mathrm{D}\right]$ glucose is used for maximal signal on the active $\mathrm{C} 1$ atom including prolonged $\mathrm{T}_{1}$ due to the deuterium. Red color indicates the hyperpolarized ${ }^{13} \mathrm{C}$ label shifting from $\mathrm{C} 1$ in glucose to $\mathrm{C} 2$ in mannose.

\section{EXPERIMENTAL METHODS}

\section{Materials}

Glucose, $\left[1-{ }^{13} \mathrm{C}\right]$ glucose and ammonium heptamolybdate tetrahydrate were purchased from Sigma-Aldrich (Andover, MA, USA). The $\left[1-{ }^{13} \mathrm{C}, \mathrm{D}\right]$ glucose was purchased from Omicron Biochemicals (South Bend, IN, USA). The radical Ox063 was obtained Oxford Instruments, (Abingdon, UK) and trimeric gadolinium chelate of 1,3,5-tris-(N-(DO3Aacetamido)-N-methyl- 
4-amino-2-methylphenyl)-[1,3,5]triazinane-2,4,6-trione was obtained from GE Healthcare (Amersham, UK).

\section{HP-NMR}

$14.5 \mathrm{mg}\left[1-{ }^{13} \mathrm{C}, \mathrm{D}\right]$ glucose was polarized in a prototype polarizer at $3.35 \mathrm{~T}$ as previously described. ${ }^{26-28}$ The sample was dissolved in $5 \mathrm{ml}$ water containing $100 \mathrm{mg} / \mathrm{L}$ EDTA. $600 \mathrm{ul}$ of the hyperpolarized glucose solution was forcefully injected into $2.4 \mathrm{ml}$ of a molybdate containing solution residing in a 14.1 T NMR spectrometer. The a molybdate solution consisted of 1.7 or $3.5 \mathrm{mg}$ of ammonium heptamolybdate tetrahydrate dissolved in $2 \mathrm{ml}$ pure water with the $\mathrm{pH}$ adjusted to the desired value using a solution of $100 \mathrm{mM} \mathrm{HCl}$. The temperature of the molybdate solution was equilibrated to $363 \mathrm{~K}$ inside a Bruker $600 \mathrm{MHz}$ Avance III NMR spectrometer equipped with a $10 \mathrm{~mm}$ broadband observe probe. A series of one-dimensional ${ }^{13} \mathrm{C}$ NMR spectra was acquired using a $10^{\circ}$ flip angle by recording one ${ }^{13} \mathrm{C}$ NMR spectrum every $500 \mathrm{~ms}$ for 2 minutes. Spectra were acquired by adding two transients of $210 \mathrm{~ms}$ acquisition with an inter-scan delay of $40 \mathrm{~ms}$, including all delays in the pulse program. 8192 complex data points were acquired for each ${ }^{13} \mathrm{C}$ spectrum.

\section{Thermal NMR on stabilized samples}

For the stabilization of reaction intermediates, $40 \mathrm{mg}$ glucose or $\left[1-{ }^{13} \mathrm{C}\right]$ glucose was mixed with $40 \mathrm{mg}$ molybdate in $600 \mathrm{ul} \mathrm{D}_{2} \mathrm{O}$ buffer at $\mathrm{pH} 4.5$ or 5.6 and $298 \mathrm{~K}$, resulting in a final ratio between glucose and molybdate of 1:0.6. Exchange spectra were recorded with mixing times between 10 and $300 \mathrm{~ms} .{ }^{1} \mathrm{H}-{ }^{13} \mathrm{C}$ NMR spectra and one dimensional ${ }^{1} \mathrm{H}$ NMR spectra were 
recorded at variable temperatures to identify previously reported molecular species and to validate chemical exchange on the sub-second timescale at increasing temperature and decreasing $\mathrm{pH}$.

\section{Data processing}

All HP NMR spectra were acquired and processed as pseudo-2D spectra in Topspin 3.5 pl5 after extensive zero filling in the acquisition domain. Manual integration was performed on individual ${ }^{13} \mathrm{C}$ spectra for the first data points and on summed ${ }^{13} \mathrm{C}$ spectra at times where polarization had faded to prohibit reliable quantification from individual transients. Highresolution spectra were acquired on an $800 \mathrm{MHz}(18.7 \mathrm{~T})$ NMR instrument equipped with a TCI cryoprobe and an Avance III console. These spectra were processed using a shifted squared sinebell apodization function after extensive zero filling in both dimensions.

\section{Data analysis}

The data from the HP dynamic series were integrated relative to the substrate signal. Such relative integration yields semi-quantitative determinations of analyte concentrations and is an approximation assuming similar $\mathrm{T}_{1}$ relaxation times of the detected species. ${ }^{29}$ This assumption is valid where measurements are fast relative to the $\mathrm{T}_{1}$ times. Measurements are conducted as presteady state measurements on the low second timescale, while $\mathrm{T}_{1}$ times of the observed positions are above 10 seconds in water at $363 \mathrm{~K}$ and $14.1 \mathrm{~T}$ magnetic field. The signals from different aldehyde forms of glucose-molybdate complexes (205-210 ppm) were added with the hydrated forms of glucose-molybdate signals (99 ppm) as the intermediates (I), as hydrated and aldose forms were found by thermal NMR to exchange on the sub-second timescale. In addition, the 
mannose complex was added to the product signal scheme in product $2(\mathrm{P})$ to simplify the fitting for the reactions of interest, molybdate complex formation and epimerization through $\mathrm{C} 1-\mathrm{C} 2$ bond cleavage. All signals were normalized to the initial value for the substrate $(\mathrm{S})$. For a satisfactory fit of the data, less than $0.2 \%$ of the substrate needed to be fitted separately as a fastreacting species with a population that is comparable to the acyclic fraction.

The signal areas for different detected molecular species were fitted to the reaction shown in scheme 1 with an in-house python script to the following coupled system of differential equations [1]-[3]:

Scheme 1. Reaction scheme used for fitting the pre-steady state kinetic of molybdate-catalyzed glucose epimerization.

\begin{tabular}{|c|c|c|}
\hline $\begin{array}{l}\text { substrate }(\mathrm{S}) \\
\text { (glucose) }\end{array}$ & $\begin{array}{l}\longrightarrow \text { intermediates (I) } \\
\text { (glucose-complexes) }\end{array}$ & $\begin{array}{l}\text { product }(\mathrm{P}) \\
\text { (mannose) }\end{array}$ \\
\hline $\mathrm{dS} / \mathrm{dt}$ & $=-\mathrm{k}_{1} * \mathrm{~S}(\mathrm{t})$ & {$[1]$} \\
\hline $\mathrm{dI} / \mathrm{dt}=$ & $=\mathrm{k}_{1} * \mathrm{~S}(\mathrm{t})-\mathrm{k}_{2} * \mathrm{I}(\mathrm{t})$ & {$[2]$} \\
\hline $\mathrm{dP} / \mathrm{dt}$ & $=\mathrm{k}_{2} * \mathrm{I}(\mathrm{t})$ & {$[3]$} \\
\hline
\end{tabular}

All fitted curves had a coefficient of determination $\left(\mathrm{R}^{2}\right)$ between 0.9 and 0.99 (see supplemental Table S1).

RESULTS

Real-time NMR to detect rare glucose tautomers under optimum reaction conditions 
Rapid injection NMR spectroscopy at $363 \mathrm{~K}$ was used to follow the molybdate-catalyzed glucose epimerization to mannose via an intramolecular 1,2 carbon shift in an attempt to characterize the reactivity of acyclic glucose species and their interaction with the catalyst at optimum reaction conditions. The optimum $\mathrm{pH}$ and temperature for the reaction are near $\mathrm{pH} 3.3$ and $363 \mathrm{~K}$, respectively,${ }^{15}$ while competing side reactions can occur at higher temperature in the acidic media. ${ }^{25}$ It has been suggested that the reaction proceeds via the open chain aldehyde ${ }^{15}$ or hydrated aldehyde ${ }^{25}$ form of glucose, which only exist transiently and in small amount (Scheme 1). In order to enhance the sensitivity for the detection of rare tautomers, $\left[1-{ }^{13} \mathrm{C}, \mathrm{D}\right]$ glucose was hyperpolarized as a vitreous syrup according to previously described procedure ${ }^{26-28}$ and injected into solutions of molybdate at $363 \mathrm{~K}$ while recording a time-resolved experiment by a series of 1D ${ }^{13} \mathrm{C}$ NMR spectra (Figure 2A). Signals vanish into the noise within 60 seconds, as the hyperpolarization procedure temporarily redistributes nuclear magnetism to a non-equilibrium state that relaxes back to the equilibrium on a time scale of seconds to few minutes.

Notably, the sensitivity enhancement provided by the hyperpolarization procedure suffices to detect acyclic hydrate and aldehyde tautomers in the presence of catalyst, alongside furanose and predominant pyranose forms (Figure 2). A molybdate complex between an open chain hydrated aldehyde form of glucose and molybdate is observed at $99.7 \mathrm{ppm}$ only in the presence of molybdate. The ${ }^{13} \mathrm{C}$ signal of the hydrate-complex is broadened, suggesting exchange between several conformations due to low affinity between the reactants. In addition to this previously described stabilized complex, ${ }^{30}$ signals arise between 205 and $210 \mathrm{ppm}$ deriving from reaction intermediates with the open chain aldehyde form of glucose in its non-hydrated form. Formation of a cyclic mannose-molybdate complex is detected at $85 \mathrm{ppm}$ and two signals for the 
dissociated reaction product D-mannose are detected near 72 ppm $(\mathrm{C}-2$ positions of the $\alpha$ - and $\beta$ pyranose forms).

Signals from the acyclic aldehyde and hydrate complexes show similar pre-steady state reaction kinetics (Figure 2B). Even though the complex signals between acyclic glucose and catalyst show similar reaction kinetics, it is evident that signals have different line widths due the broadening of signals through chemical exchange on the sub-second timescale. Both the signal at $206 \mathrm{ppm}$ and the signal at $99.7 \mathrm{ppm}$ lack the expected 1:1:1 triplet signal that results from the attachment of a single deuteron to the detected carbon atom. Both of these signals thus contain congested signals of at least two molecular species. Signals of the acyclic forms emerge rapidly after rapid injection of glucose to molybdate at levels that are considerably higher than in the absence of molybdate. Signals from acyclic glucose complexes and from the mannoseintermediate complexes were shown to increase with increasing molybdate concentrations to validate these spectral assignments (Figure 2C). 

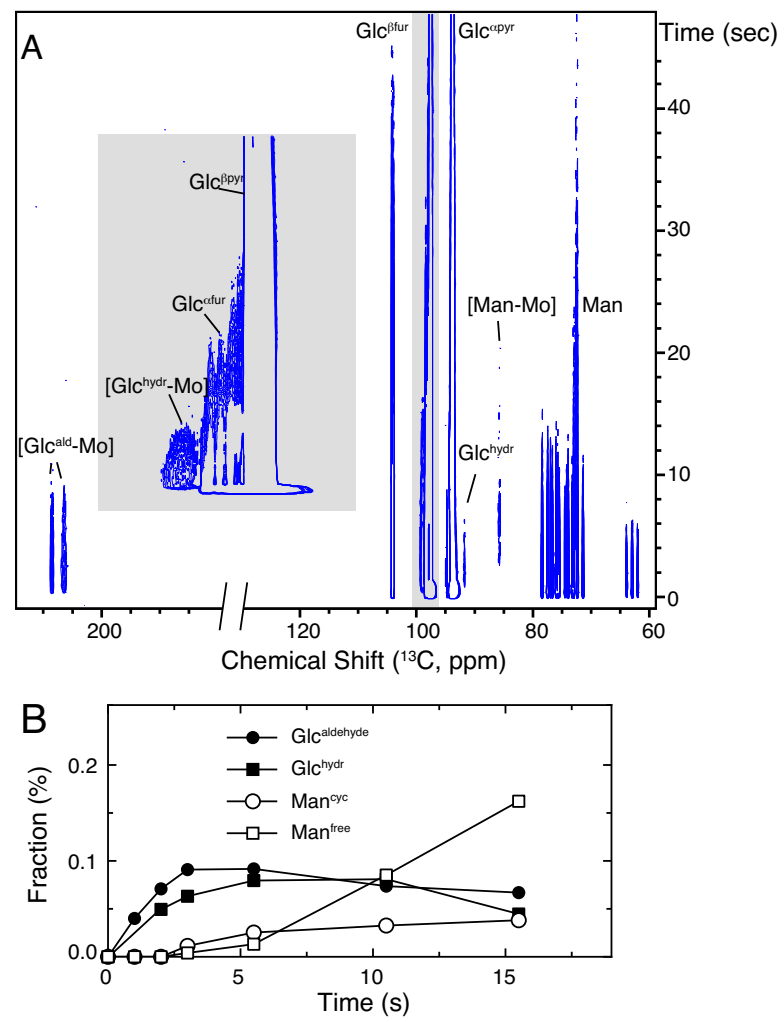

C

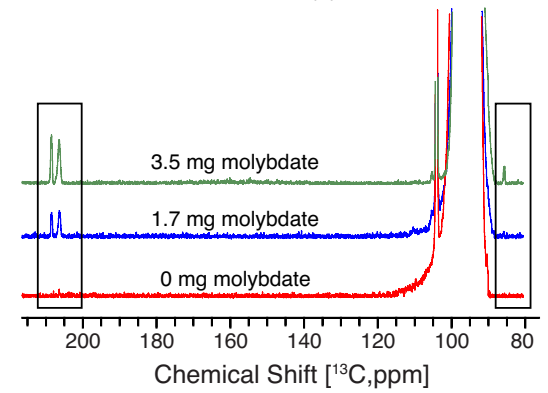

Figure 2. A) Kinetic reaction profile of the epimerization of $\left[1-{ }^{13} \mathrm{C}, \mathrm{D}\right]$ glucose to mannose using molydate as catalyst at $\mathrm{pH} 4.5$ and $363 \mathrm{~K}$. The formation of at least two complexes between the aldehyde form of glucose and the molybdate catalyst was observed at 208.5 and $206.4 \mathrm{ppm}$ (relative to ${ }^{13} \mathrm{C}$ glucose anomeric signals of $97.5 \mathrm{ppm}$ for the $\beta$-pyranose and of $93.8 \mathrm{ppm}$ for the $\alpha$-pyranose form). Also the following rearrangement molybdate complex with mannose was observed $(85 \mathrm{ppm})$ and the end product $\left[2-{ }^{13} \mathrm{C}\right] \mathrm{D}$-mannose could be followed $(72 \mathrm{ppm})$. The furanose form of glucose was observed at $105 \mathrm{ppm}$ and additional unlabeled carbon positions from glucose between 70 to $80 \mathrm{ppm}$. B) Formation to $0.1 \%$ acyclic aldehyde and hydrate complex was observed within 5 seconds of reaction time at $363 \mathrm{~K}$ and $\mathrm{pH}$ 4.5. C) Increased complex formation as function of increased molybdate concentration. A sum of the first $20{ }^{13} \mathrm{C}$ NMR spectra is shown for each molybdate concentration. 


\section{Pre-steady state reaction progress of glucose epimerization}

Subsequently, reactions were conducted at $\mathrm{pH} 3.3$ and $363 \mathrm{~K}$ to match the optimum reaction conditions, ${ }^{15,}{ }^{25}$ where D-mannose formation is increased as expected (Figure 3). Under the optimum reaction conditions, a stronger line broadening due to exchange was observed for the complex signals (Figure 3, inset). It was thus noticeable, that catalytic prowess increases with the dynamics of acyclic glucose-catalyst complexes. Multiple molybdate complexes in chemical exchange were detectable both for acyclic aldehyde and hydrate forms of glucose, while cyclic glucose-molybdate complexes were not detected. Chemical exchange in complexes of catalysts and acyclic glucose may increase the entropy of intermediates and transition states ${ }^{31}$ and facilitate catalyst-substrate binding, chemical reaction and product release. ${ }^{32}$ Beyond the increasing dynamic exchange between acyclic glucose complex forms, also the populations of the acyclic glucose-catalyst complexes increased at $\mathrm{pH} 3.3$ relative to $\mathrm{pH} 4.5$ at optimum reaction temperature, yielding steady state levels near $0.36 \%$ at $\mathrm{pH} 3.3$ and of $0.17 \%$ at $\mathrm{pH} 4.5$. 


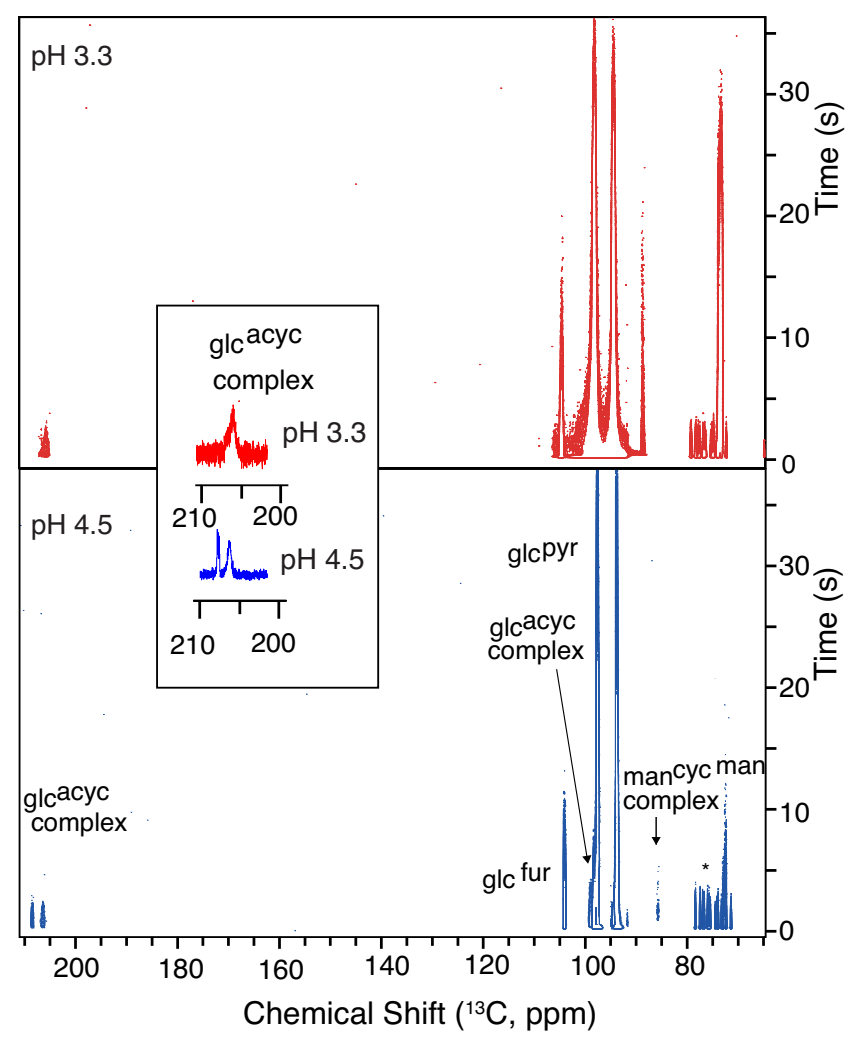

Figure 3. Comparison of reaction profiles for the epimerization of $\left[1-{ }^{13} \mathrm{C}, \mathrm{D}\right]$ glucose to mannose using molydate as catalyst at $363 \mathrm{~K}$ and at a pH of 3.3 (top) or 4.5 (bottom). The inset shows the coalescence of acyclic molybdate complex signals at lower $\mathrm{pH}$ due to increased chemical exchange at conditions of increased reactivity.

\section{Validating the presence of at least five exchanging acyclic complexes}

Due to the heterogeneity of the signals originating from the molybdate complexes observed in real-time experiments at $363 \mathrm{~K}$, we investigated the dependence of the complex formation using high field NMR under steady state conditions at suboptimal $\mathrm{pH}$ values and temperatures to stabilize the reaction intermediates (Figure 4 and 5). The $\mathrm{pH}$ was increased to 5.6 in order to reach a kinetic regime where the complexes became visible with ${ }^{1} \mathrm{H}$ NMR. Three aldehyde ${ }^{1} \mathrm{H}$ 
signals can be detected between 9.8 and $10.1 \mathrm{ppm}$ in the presence of molybdate for open-chain aldehyde complexes, consistent with the presence of two overlapping and one isolated ${ }^{13} \mathrm{C}$ aldehyde signal in the HP-NMR experiments. Increasing the temperature and decreasing the $\mathrm{pH}$ leads to exchange broadening, as anticipated from the HP-NMR experiments. This exchange broadening renders NMR studies of acyclic glucose-molybidc acid complexes very challenging at $\mathrm{pH}$ values below 4.5 even when using high-field $(800 \mathrm{MHz}) \mathrm{NMR}$ instrumentation equipped with cooled detection electronics. In addition, the ${ }^{1} \mathrm{H}$ NMR signals showing large sensitivity to temperature changes (Figure 4) resulting in a line broadening of several $\mathrm{Hz}$ due to sub-second exchange dynamics. Correspondingly, hydrate forms of acyclic glucose-molybdate complexes are detected as two broad signals (between 5.5 and $5.7 \mathrm{ppm}$ in Figure 5A, assignment based on HSQC shown in Figure S1) at pH 5.6 that show additional broadening at lower $\mathrm{pH}$.

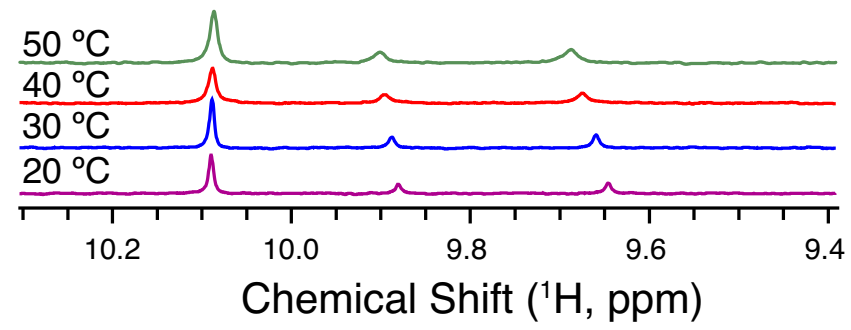

Figure 4. Detection of three aldehyde forms for glucose in the presence of molybdate by conventional ${ }^{1} \mathrm{H}$ NMR at pH 5.6 (800 MHz NMR spectrometer). Lines broaden between $293 \mathrm{~K}$ and $323 \mathrm{~K}$ due to an increasing contribution of chemical exchange to the linewidth. 
Exchange spectroscopy was used to reveal the exchange network between acyclic glucose forms in complexes with molybdate (Figure 5B). Chemical exchange on the $\sim 100$ millisecond timescale is found both among aldehyde and hydrate forms, but also between the hydrate and aldehyde forms of the acyclic glucose-complexes. The exchange among the hydrate and among the aldehyde species is consistent with the coalescence of the respective ${ }^{13} \mathrm{C}$ signals under optimum reaction conditions. Exchange between aldehyde and hydrate forms on the 100 millisecond timescale at suboptimal temperature and $\mathrm{pH}$ is consistent with the identical reaction kinetics of both forms in real time (with spectral acquisition every 500 milliseconds), at conditions with faster exchange. In addition, time scales for exchange as judged from lineshape analysis and from exchange spectroscopy are in agreement (see supplemental Figure S2).
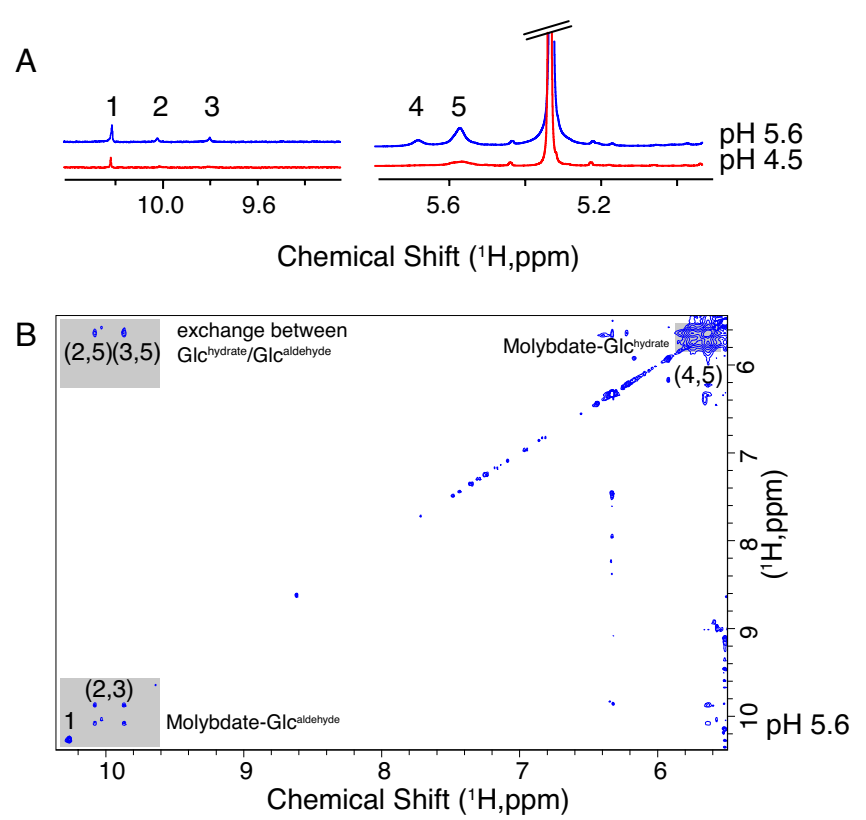

Figure 5. (A) ${ }^{1} \mathrm{H}$ spectra under steady state conditions for the glucose epimerization to mannose (313 K). Complexes with the non-hydrated (1-3) and the hydrated form (4-5) of glucose are observed. (B) EXSY spectrum $(313 \mathrm{~K}, 100 \mathrm{~ms}$ mixing time, pH 5.6). Grey areas highlight 
exchange between acyclic aldehyde and hydrate complexes on the time scale of the mixing time, with spectral species $\mathbf{1}$ being more stable than forms $\mathbf{2 - 5}$.

\section{Kinetic analysis of the ${ }^{13} \mathrm{C}$ NMR data}

The exchange between at least five acyclic glucose complexes under reaction conditions including both hydrate and aldehyde forms indicates that previous debates on the role of aldehyde and hydrate forms in the reaction is of limited importance, as these forms constitute one pool of interconverting species. Since we observe a network of exchange between acyclic glucose-catalyst complexes, we also chose to treat them together as one pool of intermediates when fitting the reaction kinetics to the time-resolved NMR data (Figure 6). Reaction rates for the rate-limiting formation of the complexes between catalyst and acyclic glucose are 300 and 1300 times slower than the epimerization at $\mathrm{pH} 3.3$ and 4.5, respectively. Protonation of the cyclic ring oxygen has been suggested as a crucial step in the formation of open chain glucose forms, which is favored by acidic conditions. Hence, reduction of the proton concentration by an order of magnitude also leads to a reduction of the rate for the first step by almost an order of magnitude. Notably, an overall epimerization rate of $1.6 \cdot 10^{-4} \mathrm{~s}^{-1}$ had been estimated at $363 \mathrm{~K}$ and pH 4.5 under equilibrium conditions, consistent with the values determined herein. Hence, sufficiently sensitivity-enhanced NMR assays can be used to accurately determine the rates of slow reactions within few seconds of experiment time in biomass conversion. 

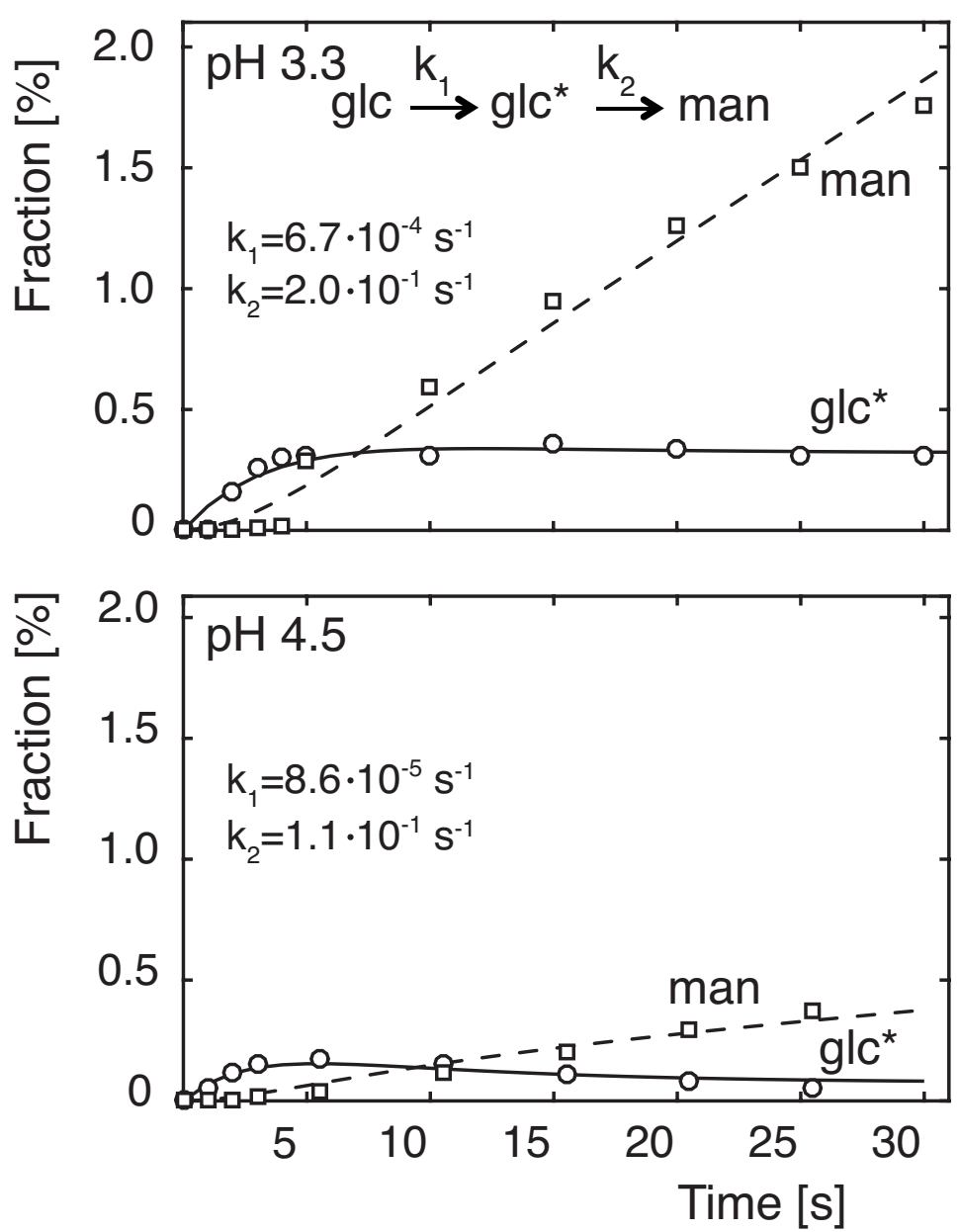

Figure 6. Kinetic analysis of glucose epimerization via an exchanging pool of acylic glucose complexes $\left(\mathrm{glc}^{*}\right)$ encompassing aldehyde and hydrate forms.

\section{DISCUSSION}

In the current study, we aimed at the detection and characterization of transient intermediates in a reaction yielding value-added product from glucose, here the epimerization of glucose to mannose. This reaction is an industrially important reaction producing value in the chemocatalytic synthesis of mannose from a cheaper and more readily available substrate. The characterization of chemical and conformational carbohydrate mixtures in solution is best conducted by NMR spectroscopy due to the high information content of the method even for 
dynamically exchanging analytes of identical mass. Using hyperpolarization methodology to temporarily enhance glucose substrate signal by $\sim 4$ orders of magnitude, we found that furanose forms, acylic complexes with $\mathrm{C} 1$ aldehyde functionality and acyclic C1-hydrates with and without bound catalyst can be detected by ${ }^{13} \mathrm{C}$ NMR spectra of less than 500 milliseconds duration. The lower limit of detection using such rapid ${ }^{13} \mathrm{C}$ NMR spectroscopy was on the order of $1 \mu \mathrm{M}$. Species that account for less than $0.05 \%$ of glucose could thus be monitored with subsecond time resolution. Hence, pre-steady state kinetic measurements of initial reaction steps become feasible upon rapid injection of the glucose into a solution containing homogeneous catalyst. Such pre-steady state methods allow the retrieval of individual rate constants of catalyzed reactions. Rate constants for the rate-determining step are determined that are consistent with values previously obtained form steady-state methods, while the concomitant C2$\mathrm{C} 3$ bond breakage and $\mathrm{C} 1-\mathrm{C} 3$ bond formation occurred two to three orders of magnitude more slowly. Acyclic molybdate complexes were formed within five seconds of the reaction, while complexation subsequently slows down and a steady state was reached. Steady state levels of the acyclic molybdate complexes were low, and the sum of five different complexes amounted to a total of less than $0.3 \%$ of all carbohydrates. Of these five different complexes, only one had been described before.

The stabilization of acyclic aldose and hydrate complexes in the presence of molybdate was directly monitored under near-optimum reaction conditions. Thus, these acylic species were visualized as the principal reaction intermediates in the molybdate-catalyzed epimerization. Formation of aldehyde complexes and formation of hydrate complexes occur with the same kinetics, indicating that the complexes form an exchanging pool of intermediates and that all acyclic glucose adducts can productively contribute to product formation. Conditions were 
identified that stabilized the complexes sufficiently to permit the detection of acyclic glucose complexes by ${ }^{1} \mathrm{H}$ spectroscopy using state-of-the art high-field NMR instruments. Conditions for stabilizing the intermediates encompassed lower temperatures $(<333 \mathrm{~K})$, less acidic $\mathrm{pH}(\mathrm{pH} 5.6)$ and a suitable glucose to molybdate ratio as well as reactant concentrations. These samples were used to validate the assignments of ${ }^{13} \mathrm{C}$ NMR spectra and to prove the presence of at least three complexes for the acyclic glucose aldehyde and of at least two complexes of acyclic glucose hydrate. Kinetic exchange on the 100 millisecond timescale was identified for acyclic glucosecatalyst complexes using lineshape analysis and exchange spectroscopy. Exchange occurs both within and between aldehyde and hydrate forms, with the exchange among the hydrate forms being fastest. Rates increase when $\mathrm{pH}$ and temperature are changed towards optimum reaction, thus showing that neither of the acylic complex forms constitutes a kinetic off-pathway trap. The heterogeneity of the dynamic intermediate complex population may favor the reaction by making intermediate formation entropically more favorable or by making substrate recruitment or conversion sterically more feasible.

\section{CONCLUSIONS}

Methodological developments in mixture analysis and sensitivity enhancement afford improved spectroscopic characterizations of acylic (and other rare) carbohydrate-tautomers. The detection of rare carbohydrate tautomers aids the detection and mechanistic study of direct carbohydrate conversion to value-added products. The most commonly used method in the study of carbohydrate conformations and tautomeric compositions has been NMR spectroscopy as the NMR signal senses chemical and conformational changes in substrate, intermediate and product 
tautomers. Modification of NMR spectroscopic approaches in conjunction with the identification of conditions and experiments that render rare intermediates detectable have permitted the experimental characterization of a low-populated exchanging pool of acyclic glucose-catalyst complexes in the epimerization to mannose. 


\section{ASSOCIATED CONTENT}

\section{Supporting Information}

${ }^{1} \mathrm{H}-{ }^{13} \mathrm{C}$ HSQC NMR spectra for identification of cyclic and acyclic glucose-molybdate complexes under conditions that stabilize the complexes. EXSY NMR spectra for determination of exchange rate and kinetic fit coefficients (PDF).

\section{AUTHOR INFORMATION}

\section{Corresponding Author}

*Correspondence should be addressed tosemei@kemi.dtu.dk or peroje@elektro.dtu.dk

\section{Notes}

The authors declare no competing financial interest.

\section{ACKNOWLEDGEMENT}

S. M. gratefully acknowledges funding by grant 2013_01_0709 of the Carlsberg Foundation. M. K. and P. R. J. gratefully acknowledge funding by the Danish National Research Foundation (grant DNRF124). $800 \mathrm{MHz}$ NMR spectra were recorded on the spectrometer of the NMR Center DTU at the Technical University of Denmark supported by the Villum foundation. 


\section{REFERENCES}

(1) Corma, A.; Iborra, S.; Velty, A. Chemical Routes for the Transformation of Biomass into Chemicals. Chem. Rev. 2007, 107 (6), 2411-2502.

(2) Gallezot, P. Conversion of biomass to selected chemical products. Chem. Soc. Rev. 2012, 41 (4), 1538-1558.

(3) Zhu, Y.; Zajicek, J.; Serianni, A. S. Acyclic Forms of [1-13C]Aldohexoses in Aqueous Solution: Quantitation by $13 \mathrm{C}$ NMR and Deuterium Isotope Effects on Tautomeric Equilibria. $J$. Org. Chem. 2001, 66 (19), 6244-6251.

(4) Barclay, T.; Ginic-Markovic, M.; Johnston, M. R.; Cooper, P.; Petrovsky, N. Observation of the keto tautomer of d-fructose in D2O using 1H NMR spectroscopy. Carb. Res. 2012, 347 (1), 136-141.

(5) Torres, A. I.; Daoutidis, P.; Tsapatsis, M. Continuous production of 5-hydroxymethylfurfural from fructose: a design case study. Energy Environ. Sci. 20103 (10), 1560-1572.

(6) van Putten, R.-J.; van der Waal, J. C.; de Jong, E.; Rasrendra, C. B.; Heeres, H. J.; de Vries, J. G. Hydroxymethylfurfural, A Versatile Platform Chemical Made from Renewable Resources. Chem.Rev. 2013, 113 (3), 1499-1597.

(7) Antal, M. J.; Mok, W. S. L.; Richards, G. N. Mechanism of formation of 5-(hydroxymethyl)2-furaldehyde from d-fructose and sucrose. Carb. Res. 1990, 199 (1), 91-109.

(8) Kimura, H.; Nakahara, M.; Matubayasi, N. In Situ Kinetic Study on Hydrothermal Transformation of d-Glucose into 5-Hydroxymethylfurfural through d-Fructose with 13C NMR. J. Phy. Chem. A 2011, 115 (48), 14013-14021. 
(9) Gunther, W. R.; Wang, Y.; Ji, Y.; Michaelis, V. K.; Hunt, S. T.; Griffin, R. G.; RománLeshkov, Y. Sn-Beta zeolites with borate salts catalyse the epimerization of carbohydrates via an intramolecular carbon shift. Nat. Com. 2012, 3, 1109.

(10) Wen, L.; Huang, K.; Wei, M.; Meisner, J.; Liu, Y.; Garner, K.; Zang, L.; Wang, X.; Li, X.; Fang, J.; Zhang, H.; Wang, P. G. Facile Enzymatic Synthesis of Ketoses. Angew. Chem. Int. Ed. 2015, 54 (43), 12654-12658.

(11) Bermejo-Deval, R.; Orazov, M.; Gounder, R.; Hwang, S.-J.; Davis, M. E. Active Sites in Sn-Beta for Glucose Isomerization to Fructose and Epimerization to Mannose. ACS Catal.2014, $4(7), 2288-2297$.

(12) Ju, F.; VanderVelde, D.; Nikolla, E. Molybdenum-Based Polyoxometalates as Highly Active and Selective Catalysts for the Epimerization of Aldoses. ACS Catal. 2014, 4 (5), 13581364.

(13) Takagaki, A.; Furusato, S.; Kikuchi, R.; Oyama, S. T. Efficient Epimerization of Aldoses Using Layered Niobium Molybdates. ChemSusChem 2015, 8 (22), 3769-3772.

(14) Bilik, V. Reactions of Saccharides Catalyzed by Molybdate Ions .2. Epimerization of DGlucose and D-Mannose. Chemicke Zvesti 1972, 26 (2), 183-186.

(15) Hayes, M. L.; Pennings, N. J.; Serianni, A. S.; Barker, R. Epimerization of Aldoses by Molybdate Involving a Novel Rearrangement of the Carbon Skeleton. J. Am. Chem. Soc. 1982 $104(24), 6764-6769$.

(16) Nguyen, H.; Nikolakis, V.; Vlachos, D. G. Mechanistic Insights into Lewis Acid Metal SaltCatalyzed Glucose Chemistry in Aqueous Solution. ACS Catal. 2016, 6 (3), 1497-1504. 
(17) van der Graaff, W. N. P.; Tempelman, C. H. L.; Li, G.; Mezari, B.; Kosinov, N.; Pidko, E. A.; Hensen, E. J. M. Competitive Adsorption of Substrate and Solvent in Sn-Beta Zeolite During Sugar Isomerization. ChemSusChem 2016, 9 (22), 3145-3149.

(18) Bertz, S. H.; Carlin, C. M.; Deadwyler, D. A.; Murphy, M. D.; Ogle, C. A.; Seagle, P. H. Rapid-Injection NMR Study of Iodo- and Cyano-Gilman Reagents with 2-Cyclohexenone: Observation of $\pi$-Complexes and Their Rates of Formation. J. Am. Chem. Soc. 2002, 124 (46), 13650-13651.

(19) Schmid, M. B.; Zeitler, K.; Gschwind, R. M. The Elusive Enamine Intermediate in ProlineCatalyzed Aldol Reactions: NMR Detection, Formation Pathway, and Stabilization Trends. Angew. Chem. Int. Ed. 2010, 49 (29), 4997-5003.

(20) Saravanamurugan, S.; Riisager, A.; Taarning, E.; Meier, S. Mechanism and stereoselectivity of zeolite-catalysed sugar isomerisation in alcohols. Chem. Comm. 2016, 52 (86), 12773-12776.

(21) Ardenkjaer-Larsen, J. H.; Fridlund, B.; Gram, A.; Hansson, G.; Hansson, L.; Lerche, M. H.; Servin, R.; Thaning, M.; Golman, K. Increase in signal-to-noise ratio of > 10,000 times in liquidstate NMR. Proc. Natl. Acad. Sci. USA 2003, 100 (18), 10158-63.

(22) Jensen, P. R.; Meier, S.; Ardenkjær-Larsen, J. H.; Duus, J. O.; Karlsson, M.; Lerche, M. H. Detection of low-populated reaction intermediates with hyperpolarized NMR. Chem. Comm. 2009, 34, 5168-5170.

(23) Lee, Y.; Heo, G. S.; Zeng, H.; Wooley, K. L.; Hilty, C. Detection of Living Anionic Species in Polymerization Reactions Using Hyperpolarized NMR. J. Am. Chem. Soc. 2013, 135 (12), 4636-4639. 
(24) Meier, S.; Jensen, P. R.; Karlsson, M.; Lerche, M. H. Hyperpolarized NMR probes for biological assays. Sensors (Switzerland) 2014, 14 (1), 1576-1597.

(25) Petruš, L.; Petrušová, M.; Hricovíniová, Z., The Bílik Reaction. In Glycoscience: Epimerisation, Isomerisation and Rearrangement Reactions of Carbohydrates, Stütz, A. E., Ed. Springer: Berlin, Heidelberg, 2001; p 15-41.

(26) Meier, S.; Jensen, P. R.; Duus, J. O. Real-time detection of central carbon metabolism in living Escherichia coli and its response to perturbations. FEBS Lett. 2011, 585 (19), 3133-3138.

(27) Meier, S.; Karlsson, M.; Jensen, P. R.; Lerche, M. H.; Duus, J. O. Metabolic pathway visualization in living yeast by DNP-NMR. Mol. Biosystems 2011, 7 (10), 2834-2836.

(28) Karlsson, M.; Jensen, P. R.; Duus, J. Ø.; Meier, S.; Lerche, M. H. Development of Dissolution DNP-MR Substrates for Metabolic Research. Appl. Mag. Res. 2012, 43 (1-2), 223236.

(29) Lerche, M. H.; Meier, S.; Jensen, P. R.; Hustvedt, S. O.; Karlsson, M.; Duus, J. Ø.; Ardenkjær-Larsen, J. H. Quantitative dynamic nuclear polarization-NMR on blood plasma for assays of drug metabolism. NMR Biomed. 2011, 24 (1), 96-103.

(30) Bilik, V.; Matulova, M. Reactions of Saccharides Catalyzed by Molybdate Ions .42. Epimerization and the Molybdate Complexes of the Aldoses. Chem. Pap. 1990, 44 (2), 257-265. (31) Wagner, C.; Kiefhaber, T. Intermediates can accelerate protein folding. Proc. Natl. Acad. Sci. USA 1999, 96 (12), 6716-6721.

(32) Ma, B.; Nussinov, R. Enzyme dynamics point to stepwise conformational selection in catalysis. Curr. Opin. Chem. Biol. 2010, 14 (5), 652-659. 
Table of content and Abstract Graphics

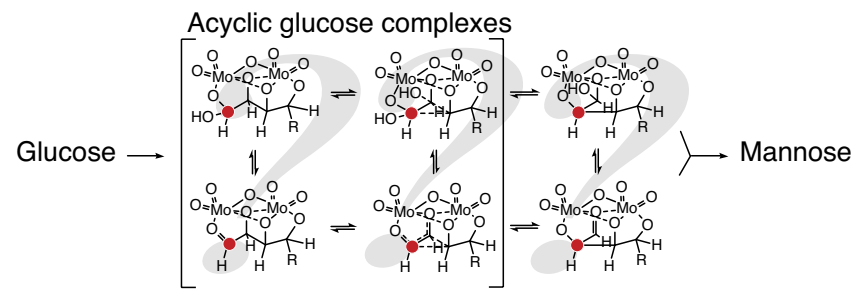

\section{TOC synopsis}

Despite of the low populations and instability under reaction conditions, the role of acyclic carbohydrates in pathways towards value-added chemicals can be visualized and characterized. 